\title{
Harnessing $\beta$-Lactam Antibiotics for Illumination of the Activity of Penicillin-Binding Proteins in Bacillus subtilis
}

\author{
Shabnam Sharifzadeh, \\ Departments of Chemistry, University of Minnesota, Minneapolis, Minnesota 55455, United States \\ Felix Dempwolff, \\ Department of Biology, Indiana University, Bloomington, Indiana 47405, United States \\ Daniel B. Kearns, \\ Department of Biology, Indiana University, Bloomington, Indiana 47405, United States \\ Erin E. Carlson \\ Departments of Chemistry, Medicinal Chemistry, and Biochemistry, Molecular Biology and \\ Biophysics, University of Minnesota, Minneapolis, Minnesota 55455, United States
}

\begin{abstract}
Selective chemical probes enable individual investigation of penicillin-binding proteins (PBPs) and provide critical information about their enzymatic activity with spatial and temporal resolution. To identify scaffolds for novel probes to study peptidoglycan biosynthesis in Bacillus subtilis, we evaluated the PBP inhibition profiles of $21 \beta$-lactam antibiotics from different structural subclasses using a fluorescence-based assay. Most compounds readily labeled PBP1, PBP2a, PBP2b, or PBP4. Almost all penicillin scaffolds were coselective for all or combinations of PBP2a, 2b, and 4. Cephalosporins, on the other hand, possessed the lowest $\mathrm{IC}_{50}$ values for PBP1 alone or along with PBP4 (ceftriaxone, cefoxitin) and 2b (cefotaxime) or 2a, 2b, and 4 (cephalothin). Overall, five selective inhibitors for PBP1 (aztreonam, faropenem, piperacillin, cefuroxime, and cefsulodin), one selective inhibitor for PBP5 (6-aminopenicillanic acid), and various coselective inhibitors for other PBPs in B. subtilis were discovered. Surprisingly, carbapenems strongly inhibited PBP3, formerly shown to have low affinity for $\beta$-lactams and speculated to be involved in $\beta$-lactam resistance in $B$. subtilis. To investigate the specific roles of PBP3, we developed activity-based probes based on the meropenem core and utilized them to monitor the activity of PBP3 in living cells. We showed that PBP3 activity localizes as patches in single cells and concentrates as a ring at the septum and the division site during the cell growth cycle. Our activity-based approach enabled spatial resolution of the transpeptidation activity of
\end{abstract}

\footnotetext{
Corresponding Author Erin E. Carlson carlsone@umn.edu.

The Supporting Information is available free of charge at https://pubs.acs.org/doi/10.1021/acschembio.9b00977.

Additional gel and microscopy images, data tables, proteomics and MIC data, materials and methods, and small molecule synthesis information and characterization data (PDF)

The authors declare no competing financial interest.

DEDICATION

We dedicate this work to Professor Laura L. Kiessling on the occasion of her 60th birthday. Her beautiful work in the area of bacterial cell wall biosynthesis inspired us to pursue this exciting field!
} 
individual PBPs in this model microorganism, which was not possible with previous chemical and biological approaches.

\section{Graphical Abstract}
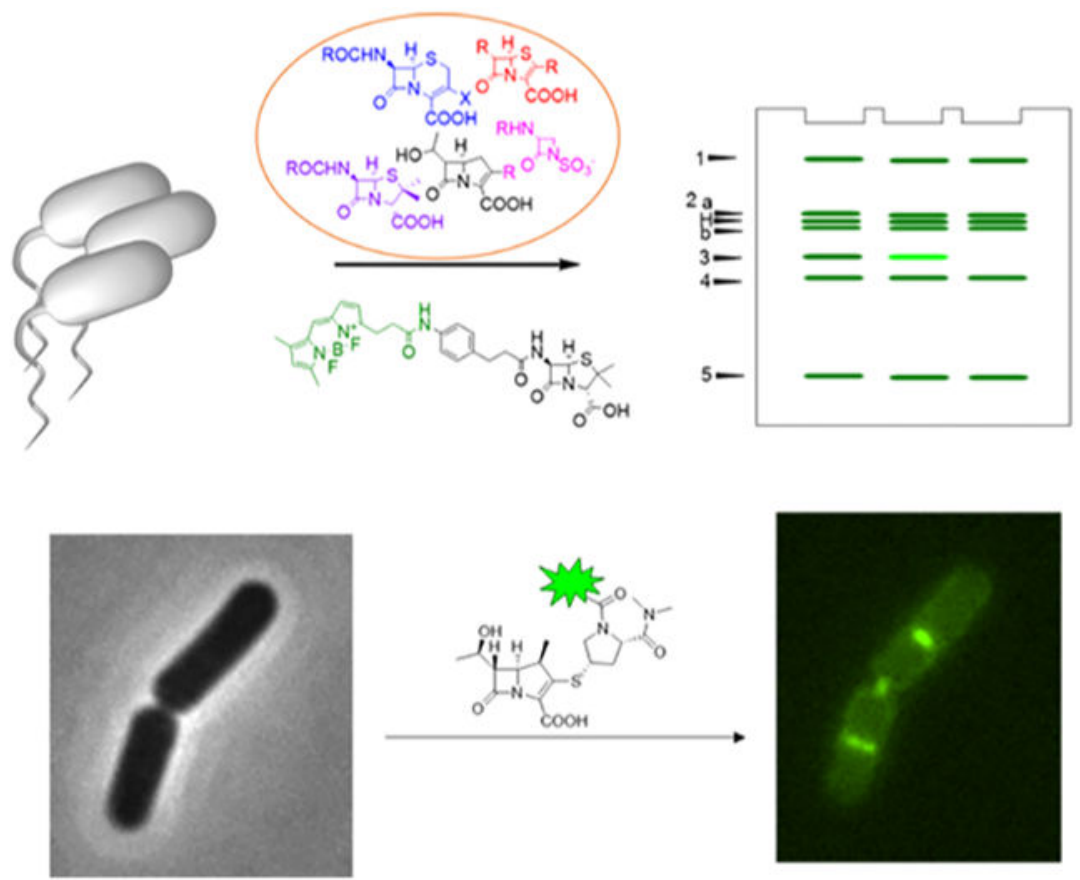

\section{INTRODUCTION}

Bacterial cell shape and integrity are dictated by the rigid external layer that surrounds the cell, known as the cell wall. A major component of this protective coating, which is unique to prokaryotes, is the peptidoglycan (PG), a heteropolymeric structure composed of saccharide backbones that are cross-linked by peptide subunits (Figure 1). ${ }^{1} \mathrm{PG}$ composition and structure are linked to cell wall thickness and integrity, hence determining sensitivity to cell-wall-targeting antibiotics and host immunity. ${ }^{2}$ Biosynthesis of the PG requires the coordinated action of multiple bacterial enzymes. Of great significance are the penicillinbinding proteins (PBPs), which mediate the final steps of PG assembly through polymerization and cross-linking of the PG chains (Figure 1). ${ }^{3,4}$ PBPs are classified based on their molecular weight and conserved amino acid motifs. PBPs are divided into two main subclasses based on their molecular mass: high molecular mass (HMM) and low molecular mass (LMM). HMM PBPs are composed of multiple domains and are involved in the polymerization and cross-linking of the PG chains, two processes known as transglycosylation (TG) and transpeptidation (TP), respectively. Based on the number of reactions that each enzyme can catalyze, HMM PBPs are further classified. While class A proteins are bifunctional and catalyze both TG and TP processes, class B PBPs only catalyze the latter. LMM PBPs, which are also referred to as class $\mathrm{C}$, catalyze a different process called D,D-carboxypeptidation, during which the stem pentapeptide is hydrolyzed to a tetrapeptide. ${ }^{3,4}$ 
PBPs were discovered and named for their affinity to bind to $\beta$-lactam antibiotics such as penicillin, which comprise the largest class of clinically utilized antibiotics today by virtue of their high efficacy and the availability of numerous derivatives. Since the breakthrough discovery of penicillin $\mathrm{G}$ in the 1920s, numerous derivatives of penicillin and other classes of $\beta$-lactams such as cephalosporins, monobactams and carbapenems have been discovered. Each new class of $\beta$-lactams has been developed for two main reasons: (1) to counteract the resistance evolved by bacteria, which is primarily due to expression of $\beta$-lactamase enzymes that hydrolyze the $\beta$-lactam ring. A famous example of this case is methicillin that was developed in 1959 to treat Staphylococcus aureus strains that had become resistant to penicillin G; or (2) to increase the spectrum of activity, such as carbapenems which have a broad spectrum of activity against Gram-positive and Gram-negative aerobic and anaerobic organisms and are used for treating complicated life-threatening infections that do not respond to standard antibiotic therapies. 5,6

Most bacteria possess a relatively large suite ofPBPs between $\sim 4-16$ homologues. $1,4,7,8$ Although the importance of the PBPs as antibacterial targets has long been appreciated, the specific roles of individual PBPs, beyond their catalytic function, has remained elusive due to the lack of appropriate chemical and biological tools. ${ }^{9,10}$ Functional redundancy within the PBPs has compounded the difficulties in establishing the role of individual PBPs in peptidoglycan biosynthesis. ${ }^{11-13}$ Single PBPs have been studied by conjugation to fluorescently labeled protein tags. ${ }^{12,14}$ However, these data alone are insufficient to fully characterize their roles as protein localization does not provide information about the activity state of the PBPs. Moreover, protein tags are bulky and can perturb protein abundance, localization, or function. ${ }^{15}$ Alternatively, fluorescent D-amino acids (FDAAs) have been developed that can be incorporated into nascent cell wall, reporting on the formation of new PG material, but do not provide protein homologue-specific information. 16-19 As such, we have pursued the identification of small molecule scaffolds with high affinity for individual homologues that enable selective targeting of individual PBP catalytic activities.

The earliest strategy for detection of PBP activity was tagging of these proteins with radiolabeled penicillin, followed by separation by sodium dodecyl sulfate polyacrylamide gel electrophoresis (SDS-PAGE). As suicide inhibitors of the PBPs, radioactive penicillins provide information about the catalytic state of the PBPs, and as such, they have been used in kinetic and inhibitor binding assays. ${ }^{20-22}$ More recently, fluorescent probes replaced their radioactive counterparts due to their added advantages, including application to live cells, imaging potential, and faster, lower hazard procedures. Bocillin-FL (Boc-FL), a fluorescent derivative of penicillin $\mathrm{V}$, is a global probe that typically labels all PBPs in a given organism. 23,24 Following this advancement, we and others have utilized fluorescence-based assays for profiling PBP inhibition using Boc-FL as the readout probe from live cells. ${ }^{24,25}$ Moreover, fluorescent penicillin-based probes have enabled monitoring of PBP transpeptidation activity in live cells. ${ }^{23,26,27}$ Previously, we generated fluorescent Ceph C-based probes that demonstrated selectivity for a subset of PBPs and used them to label active PBPs in Grampositive bacteria. ${ }^{9}$ More recently, we developed a class of PBP-selective probes using a $\beta$ lactone scaffold and visualized the activity of individual transpeptidases in $S$. pneumoniae. ${ }^{10}$ 
Given the proven success of our probe toolbox, we aimed to develop probes for individual PBPs in Bacillus subtilis.

B. subtilis is a sporulating Gram-positive organism with a large number of PBPs. In 1972, Strominger demonstrated the presence of five different penicillin-binding components in $B$. subtilis. ${ }^{28}$ Today, 16 genes are known to encode PBPs in this microorganism, which include four class A, six class B, and six class C PBPs. ${ }^{10,11,14,29}$ Some of these PBPs play roles in cell growth and division, ${ }^{11,14,30}$ while others are involved in synthesis of the spore PG. ${ }^{31-35}$ However, as described previously, the specific tasks of individual members have been difficult to assign due to functional redundancy of these enzymes. ${ }^{11,12,14,34}$ To facilitate the development of chemical tools to study cell growth and division in B. subtilis, we assessed the PBP inhibition profile of a library of $\beta$-lactam antibiotics in this model microorganism using the fluorescent whole cell assay mentioned above. Briefly, B. subtilis cells were treated with increasing concentrations of different $\beta$-lactam antibiotics followed by Boc-FL as the readout probe to determine which PBPs were blocked by the antibiotic. Subsequently, cells were lysed, and the membrane fraction was analyzed by SDS-PAGE. As expected, several PBP targeting profiles were observed for each $\beta$-lactam structural subclass, among which the high affinity of carbapenems for PBP3, a transpeptidase known for low sensitivity to $\beta$-lactams, stood out. To investigate the activity of PBP3, we designed and synthesized probes based upon meropenem. Our meropenem-based probes retained the PBP binding profile of the core meropenem molecule and specifically targeted PBP3 and PBP5. We then applied the probes to the B. subtilis DK654 strain, in which dacA, encoding PBP5, is knocked out to enable specific visualization of PBP3. Fluorescent imaging revealed a distinct localization pattern for PBP3 with a high concentration of activity at the septal region and the separation site in the mid- to late-divisional stage. Interestingly, inhibition of the only essential PBP in B. subtilis, PBP2b, via pretreatment of the cells with mecillinam did not change the labeling pattern, which suggests that PBP3 acts independently and complements PBP2b activity.

\section{RESULTS}

\section{Selectivity Profile of $\beta$-Lactams for $B$. subtilis PBPs.}

Herein, $21 \beta$-lactam antibiotics from different subclasses (penicillin, cephalosporin, carbapenem, penem, and monobactam) were tested in B. subtilis PY79 strain to determine their PBP binding profile (Figure S1). This is the first example of a comprehensive in vivo profiling of the PBP activity in this model microorganism. Results are presented as gel images and graphs in Figures S2. For each gel, the fluorescence intensity of individual bands was measured and compared with the corresponding PBP band from a parallel sample not treated with antibiotics. The average of these relative intensity values from two independent assays was plotted against antibiotic concentration to calculate the $\mathrm{IC}_{50}$ values of individual PBPs for each compound (Table 1). A compound was considered selective for a specific PBP if the measured $\mathrm{IC}_{50}$ was at least four-fold lower than that of the next most inhibited PBP (smaller $\mathrm{IC}_{50}$ ). When the $\mathrm{IC}_{50}$ value for a second, third, or fourth PBP fell below this threshold, that compound was considered coselective for all of the most inhibited PBPs. Selectivity criteria were the same as described previously. ${ }^{24,25}$ 
Five of the tested $\beta$-lactams, including aztreonam, faropenem, piperacillin, cefuroxime, and cefsulodin, were selective for PBP1, which is a class A HMW PBP in this microorganism. 6Aminopenicillanic acid (6-APA) selectively inhibited PBP5, the only LMM PBP active in the vegetative state of $B$. subtilis, at submicromolar concentrations. The finding that 6-APA acted as PBP5 inhibitor is in contrast with our previous work that indicated the low affinity of this compound for any PBPs in S. pneumoniae and E. coli. ${ }^{24}$ Aside from PBP1 and PBP5, coselective inhibition of multiple PBPs was observed by the remainder of the $\beta$-lactams (Table 1). All tested cephalosporins except cephalexin were selective or coselective inhibitors of PBP1, which is one of the class A PBPs in B. subtilis. Aztreonam and faropenem, a monobactam and a penem, also showed high affinity for this PBP. On the other hand, piperacillin was the only compound from the penicillin subclass that resulted in complete inhibition of this PBP within the tested concentrations (Figures 2 and S2). These findings are in contrast with a previous report on titration of B. subtilis membrane lysates by $\left[{ }^{14} \mathrm{C}\right]$ penicillin $\mathrm{G}$ followed by SDS-PAGE and fluorography, which revealed that PBP1a, $1 \mathrm{~b}$, and $2 \mathrm{c}$ saturate at very low concentrations, followed by PBPs $2 \mathrm{a}$ and $4 .{ }^{36}$ Moreover, another report suggested penicillins such as mecillinam, methicillin, and ampicillin as strong inhibitors of both PBP1 and 2 from B. subtilis membrane lysates. ${ }^{37}$ In another study on Bacillus megaterium, which is similar to $B$. subtilis, whole cells were treated with $\left[{ }^{14} \mathrm{C}\right]$ penicillin $\mathrm{G}$, and PBP1 was suggested as the main target for this $\beta$-lactam. ${ }^{38}$ The results of these studies are inconsistent with our work, which indicates the potentially significant difference between the activity of PBPs in vivo versus in cell lysates, demonstrating the utility of our strategy. ${ }^{24,34}$

Based on the molecular weight and labeling experiments with PBP knock out strains, we determined that $\mathrm{PBPH}$ is comigrating with PBP2b under our assay conditions (Figure S3). PBPH is a class B transpeptidase with high structural similarity to PBP2a. ${ }^{11}$ Deletion of $p b p H$ does not cause phenotypic changes. However, $\triangle p b p A \Delta p b p H$ double mutants are not viable. ${ }^{11}$ Comparison of the fluorescence intensity between wild-type and the $\Delta p b p H$ strain labeled by Boc-FL, a measure of TP activity, revealed no significant difference in the relative activity for most of the PBPs (Figure S3, Table S1). Moreover, titrations with ampicillin (PBP2a, 2b, and 4 inhibitor) and methicillin (PBP2a and 2b inhibitor) were performed with DK694 ( $\Delta p b p H)$ cells (Figure S4), and gel bands for all PBPs were quantitated to confirm the relatively minor contribution of $\mathrm{PBPH}$ to the $\mathrm{IC}_{50}$ values for the comigrating PBP2b. $\mathrm{IC}_{50}$ values for individual PBPs were comparable and within twofold in most cases (Table S2). These results are consistent with the fact that PBPH activity is minimal in the early log phase and becomes prominent only in the late exponential phase. Given the minimal contribution of PBPH activity to fluorescent labeling observed in the $\mathrm{PBP} 2$ region, $\mathrm{PBP} 2 \mathrm{~b}$ and $\mathrm{PBPH}$ were integrated together, and the resulting value was used as a measure of PBP2b activity.

In this study, all tested penicillins were potent inhibitors of PBP2a and PBP2b with calculated $\mathrm{IC}_{50}$ values in the submicromolar range for most compounds with the exception of 6-APA, as mentioned previously. Mecillinam exclusively targeted PBP2a and PBP2b over the tested range of concentrations (Figures 3 and S2). Mecillinam is a specific inhibitor of PBP2 in E. coli, preventing lateral cell wall elongation, causing formation of spherical cells incapable of dividing and ultimately leading to cell death. ${ }^{39-41} \mathrm{PBP} 2 \mathrm{a}$ has long been 
believed to play roles in maintaining rod shape in $B$. subtilis, and mutation in PBP2a has been found to cause twisted cells..$^{11,42,43}$ PBP2b, encoded by $p b p B$, is the only PBP that is essential for growth in $B$. subtilis, which is attributed to its major role in septum formation. $12,43,44$ More recently, it was revealed that the transpeptidation activity of PBP2b is dispensable, and cells containing deactivated PBP2b maintain normal growth and morphology. ${ }^{12,13}$ Thus, the development of chemical tools that can selectively target the activity of these transpeptidases can complement the genetic studies and deepen our knowledge about these PBPs, which will be the subject of future work.

All tested compounds showed the highest affinity for class A HMW PBPs except for 6-APA (PBP5 inhibitor) and the two tested carbapenems, doripenem and meropenem, which selectively inhibited PBP3 and PBP5, a class B transpeptidase and a D,D-carboxypeptidase, respectively (Figure 4A). Interestingly, these two carbapenems yielded very low MIC values, $0.0625 \mu \mathrm{g} / \mathrm{mL}$, at which most PBPs are only minimally inhibited (Figure 4A, Figure 5). To investigate whether growth in the presence of meropenem might affect the PBP activity profile after an extended period of exposure, we grew B. subtilis cells with a sub-MIC concentration of meropenem $(0.01 \mu \mathrm{g} / \mathrm{mL}, 2 \mathrm{~h})$ and examined the PBP activity profile. No significant inhibition ofany PBP occurred under these conditions, perhaps suggesting an additional role for meropenem that leads to cell death (Figure S5).

\section{Lethal Target(s) of $\beta$-Lactams in B. subtilis.}

Relying on our titration and growth inhibition results, we sought to determine the main killing target(s) for the tested $\beta$-lactams. Minimum inhibitory concentration (MIC) values were plotted against $\mathrm{IC}_{50}$ values for every PBP separately (Figure S6). No conclusive relationship could be drawn between inhibition of any specific PBP and cell growth. This is in contrast to our previous work in $S$. pneumoniae that yielded an obvious relationship between the MIC value and inhibition of one of the essential PBPs, PBP2x. ${ }^{45}$ Given the essentiality of PBP2b, one might expect that substantial inhibition $(>50 \%)$ of this protein would be required for cell killing. This is not the case with aztreonam, meropenem, 6-APA, oxacillin, or cloxacillin, further supporting the recent demonstration that abolishment of its TP activity is tolerated. ${ }^{12,13}$ However, a closer look at the profile of the PBPs targeted at inhibitory concentrations of individual compounds reveals some interesting trends within different $\beta$-lactam subclasses. Penicillins completely blocked PBP2a and PBP2b as well as one or more additional PBPs at sub-MIC levels (Table S3). The only exception is 6-APA, which consists of only the penicillin core with no side chain. At growth inhibitory concentrations, 6-APA failed to significantly block any PBPs. All cephalosporins, excluding cephalexin, targeted PBP1 under sub-MIC concentrations. The same results were observed with aztreonam and faropenem, a monobactam and a penem, respectively (Table S3, Figure 5). While this cumulative data might implicate all of these PBPs as potential lethal targets in B. subtilis, our results with 6-APA, as mentioned, along with meropenem and doripenem, immediately contradict this hypothesis. Considering the different growth conditions for PBP labeling (i.e., PBS) vs MIC assays (i.e., LB), it is possible that individual PBPs may have varying roles and importance during different stages of cell division. 


\section{Development of Meropenem-Based Probes to Target PBP3.}

According to our results, among the transpeptidases in B. subtilis, PBP3 has the lowest susceptibility to $\beta$-lactams. The only exceptions were the carbapenems (Table 1 ). Given the unique affinity of the carbapenems for PBP3 (Figure 4A), we designed chemical probes based upon meropenem to target the activity of this protein (50\% inhibition observed at 0.26 $\mu \mathrm{g} / \mathrm{mL}$ corresponding to $0.67 \mu \mathrm{M}$, and complete inhibition at $1 \mu \mathrm{g} / \mathrm{mL}$ of meropenem corresponding to $2.6 \mu \mathrm{M}$ ). Although none of the tested inhibitors only targeted PBP3, we pursued the development of a meropenem-based probe as this scaffold should label PBP3 and PBP5 and could be used in conjunction with a pbp5 deletion mutant ( $\triangle$ dacA; DK654) to readily visualize PBP3 activity, as we have done in previous studies. ${ }^{10,27}$

The secondary amino group located in the pyrrolidine ring of meropenem was used to attach a fluorophore to enable visualization of the TP activity (MEM-BODIPY; Scheme S1).

Another analogue containing an alkyne side chain, click-MEM, was produced to enable installment of different reporter and affinity tags through the copper(I)-catalyzed Hüisgen azide-alkyne cycloaddition (CuAAc; Figure 4B). Both probes retained specificity for PBP3 and PBP5, identical to the core meropenem molecule (Figure 4C). Assessment of the PBP targeting profile in strains in which PBP3 or PBP5 were knocked out, DK695 $(\Delta p b p C)$ and DIK654 ( $\triangle d a c A)$, respectively, confirmed these proteins as the targets of our meropenembased probes (Figure S7). To further confirm this, we tagged the $B$. subtilis proteome with click-MEM and installed a biotin affinity tag via CuAAc. Biotinylated proteins were subsequently enriched by Neutravidin-agarose beads, subjected to proteolytic digestion by trypsin, and the resulting peptide mixture was analyzed by LC-MS/MS. The obtained data were searched against the $B$. subtilis FASTA amino acid sequence database and confirmed that PBP3 and PBP5 were enriched as expected (Figure S9). Three other proteins were enriched along with these PBPs that are known to have roles in phosphoenolpyruvatedependent sugar phosphotransferase system (PtsI), purine metabolism (GuaA), and synthesis of ATP (AtpD). While our results prove the ability of our chemical proteomics platform to investigate the potential cellular targets of meropenem molecule, further studies are needed before drawing any conclusions about such targets.

\section{PBP Imaging in $B$. subtilis Using $\beta$-Lactam Probes.}

PBPs of $B$. subtilis have been previously visualized in vivo using fluorescent protein tags or antibodies. ${ }^{12,14}$ We were interested in using our meropenem-based probes to visualize the activity of PBPs and establish their potential for imaging studies. We utilized the MEMBODIPY FL probe to monitor PBP3 activity in B. subtilis DK654, in which PBP5 is knocked out, and therefore, our MEM-BODIPY FL probe specifically targets PBP3. The images showed that PBP3 localized in the septal region as a ring in early to-mid divisional cells and moved to the separation site during late divisional stages (Figure 6). We also observed either patch-like or polar distribution of fluorescence signal in single cells (Figures 6 and S10). Control experiments were carried out using the BODIPY dye to rule out nonspecific binding of fluorophore molecule and background fluorescent signal (Figure S11). Additionally, fluorescent signal was significantly reduced upon pretreatment of the cells with $10 \mu \mathrm{g} / \mathrm{mL}$ meropenem, which blocks PBP3 activity (Figures S12 and S13). Our results were in contrast with a previous study that used fluorescent protein tags to localize 
PBPs in B. subtilis and reported that a fluorescent PBP3 construct distributed around the cell periphery and was not enriched at the site of the septum. ${ }^{14}$ This difference in results could be due to the fact that the chemical labeling indicates the location of PBP3 activity, but our findings are consistent with a recent study in which $B$. subtilis PBP3 was immunolabeled and showed predominant localization at midcell and the cell poles. ${ }^{12}$ We conclude that either the fusion of the fluorescent protein to PBP3 caused localization artifacts or PBP3 is dynamic in localization and activity.

Next, we sought to employ our Click-MEM probe for the same purpose because the alkyne functionality would enable installation of different reporter groups in the future. Performing the labeling and click chemistry in phosphate buffer saline led to lysis of the majority of the cells. We found that performing these steps in minimal media would overcome this problem. However, the background fluorescence signal remained high in comparison to the MEMBODIPY FL probe (Figures S10 and S11).

PBP2b is the only essential PBP in B. subtilis with established roles in cell division. It was recently shown that the transpeptidation activity of PBP2b is dispensable, and PBP3 becomes the essential transpeptidase once PBP2b is deactivated. ${ }^{12}$ To target PBP3 in the absence of PBP2b activity, DK654 cells were pretreated with $10 \mu \mathrm{g} / \mathrm{mL}$ mecillinam, which we have shown to selectively inhibit PBP2b (Table 1, Figure S2). Fluorescence imaging of cells pretreated with mecillinam revealed similar labeling at the septum of the dividing cells and patch-like labeling of the single cells when compared to cells that were not pretreated (Figure S14).

\section{DISCUSSION}

Although PBP TP activity is fundamental to normal bacterial physiology, it has not been possible to conclusively determine which PBPs may be most critical for TP activity in live cells. PBPs in B. subtilis have long been studied as the targets of $\beta$-lactam antibiotics. The covalent nature of the complex formed between $\beta$-lactams and PBPs has made them invaluable tools, aside from their therapeutic utility, for both isolation ${ }^{28}$ and analysis of this family of enzymes. ${ }^{9,23,24,26,35,37,46}$ Studies of $\beta$-lactam selectivity in $B$. subtilis and other microorganisms have been conducted for two main purposes: (1) $\beta$-lactam binding studies to identify those PBPs directly related to measured MICs, which reveals that those PBPs are potentially essential for the growth of the microorganism; and (2) studies on strains resistant to specific $\beta$-lactams to identify which PBPs show a change in sensitivity for that antibiotic and if those PBPs play a role in resistance. ${ }^{8}$ Radioactive penicillins were initially exploited to tag PBP activity in bacterial lysates in such experiments. ${ }^{24,28,35-38,42,47-49}$ In spite of the invaluable information that these in vitro studies have provided about the affinity of $\beta$ lactams for PBPs, it must be noted that membrane proteome preparation could potentially affect and change protein activity. ${ }^{50}$ Therefore, we performed a comprehensive study and titrated $B$. subtilis cells with an extensive library of $\beta$-lactams using a fluorescent whole cell assay.

B. subtilis has been extensively studied as a Gram-positive model microorganism. As part of its cell wall biosynthesis machinery, B. subtilis possesses four class A PBPs that polymerize 
PG, known as PBP1, 4, 2c and 2d, encoded by genes $p o n A, p b p D, p b p F$, and $p b p G$, respectively. ${ }^{34,51-53}$ Construction of mutant strains lacking one or multiple class A PBPencoding genes revealed that only loss of PBP1 results in significant phenotypic and PG structure changes. ${ }^{30,54,55}$ Simultaneous deletion of PBP1 and PBP4 accentuates PG structural defects with a profound decrease in growth rate. ${ }^{54} \mathrm{PBP} 2 \mathrm{c}$ and PBP2d are known to play roles mainly in spore PG synthesis. ${ }^{34}$ In our titration studies, we found many selective inhibitors for PBP1, which could be used to further investigate the roles and regulation of this PBP. Additionally, several penicillins and a few cephalosporin compounds, including ceftriaxone, cephalothin and cefoxitin, resulted in very low $\mathrm{IC}_{50}$ values for PBP4. Overall, all tested compounds except carbapenems, mecillinam, and 6-aminopenicillanic acid favored PBP1, PBP4, or both as their main target in B. subtilis. This substantial preference for class A HMM PBPs is in contrast with our preceding results in other microorganisms, in which LMM PBPs were favored. In our previous work on $S$. pneumoniae, another Gram-positive microorganism, the most inhibited PBPs were 3, followed by $2 \mathrm{x}$, which are LMM and class B HMM PBPs, respectively. ${ }^{24}$ Similarly in $E$. coli, a rod shape model organism, we found that PBP3, a class B transpeptidase, as well as PBPs 4, 7, and 8, all LMM PBPs, were targeted more frequently compared with class A HMM PBPs. ${ }^{24}$

The primary lethal target(s) of $\beta$-lactams in $B$. subtilis is still under debate. Two main strategies have been employed to investigate lethal targets of $\beta$-lactams in different microorganisms. One method is to identify the PBPs that are inhibited the most at concentrations leading to growth inhibition. ${ }^{37}$ An alternative method is to determine which PBPs show altered activity in mutant strains, assuming that decreased affinity of certain PBPs has caused resistance. ${ }^{35}$ Early gel-based studies on B. subtilis, performed prior to resolution of PBP2a and PBP2b, identified PBP2 as the main killing target of $\beta$-lactams in this microorganism. ${ }^{35,42,47}$ PBP2 was identified as the main killing target of cloxacillin in $B$. subtilis strain Porton and carbenicillin-resistant mutants. ${ }^{35,47}$ However, affinity of PBP2 from mutant strains for penicillin did not change in this study, which could raise the possibility of distinct modes of interaction for different $\beta$-lactam molecules with the penicillin-binding site of the enzyme. ${ }^{35}$ Upon resolving the PBP2 band into PBP2a and PBP2b, the former was suggested as the lethal target, ${ }^{47}$ although PBP2b was never completely eliminated as the other potential option. ${ }^{14}$ Moreover, $B$. subtilis strains lacking PBP2a or PBP3 have been shown to become more sensitive to $\beta$-lactams. ${ }^{12}$ We did not find any specific correlations between the inhibition of any PBP and inhibition of growth in $B$. subtilis (Figure S6). However, we noted that in general, at the MICs, at least one HMM PBP must be fully blocked (Figure 5).

Among the currently available $\beta$-lactam antibiotics, carbapenems have gained a unique status due to their broad spectrum of antibacterial activity and resistance to hydrolysis by different classes of $\beta$-lactamases or even inhibition of these enzymes in some cases. ${ }^{6,56}$ Previous in vitro studies have shown that carbapenems induce morphological changes in Pseudomonas aeruginosa strains in a time- and concentration-dependent manner. ${ }^{57,58}$ Meropenem and doripenem are particularly potent for the inhibition of PBP2 and PBP3 in $P$. aeruginosa and PBP2 in E. coli, both rod-shaped Gram-negative organisms. ${ }^{59}$ Morphological studies in $P$. aeruginosa revealed that both meropenem and doripenem cause filamentation 
with a central oval swelling and no significant cell wall breakage and lysis. ${ }^{58,60,61}$ In our titration studies, both doripenem and meropenem showed a distinct PBP binding profile, selectively inhibiting PBPs 3 and 5. PBP3, encoded by $p b p C$, is a class B HMW transpeptidase which is mostly expressed during the vegetative phase. The activity ofPBP 3 is dispensable in wild type cells. Mutations in $p b p C$ were shown to cause helical cells with no significant effect on peptidoglycan composition ${ }^{12,13,42}$ and increased susceptibility to $\beta$ lactams. ${ }^{12,42}$ Analysis of the primary sequence of PBP3 revealed significant similarity to Enterococcus faecium PBP5, S. aureus PBP2a, and E. coli PBP2. ${ }^{62}$ More recently, the essential role of PBP3 in the absence of PBP2b activity in cell division was discovered. ${ }^{12,13}$ Visualization of PBP3 activity in live $B$. subtilis by chemical probes as presented in this work also suggested a potential role for this PBP in cell division, which seems to proceed independently from PBP2b TP activity. Future studies will benefit from this methodology to further explore PBP3 and PG transpeptidation in B. subtilis and other bacterial systems. Finally, biotin-mediated enrichment of meropenem-tagged proteins from whole cells enabled the isolation of PBP3 and PBP5, highlighting the utility of our chemical tools for investigation of the PBPs and the proteins associated with them.

\section{CONCLUSION}

Herein, we presented the first extensive analysis of PBP inhibition profiles of the $\beta$-lactam antibiotics in $B$. subtilis cells. Several compounds showed dose-dependent selectivity for a single PBP, while the remainder of the molecules inhibited multiple PBPs. Additionally, mecillinam stood out as a specific inhibitor of PBP2b (predominantly) and PBP2a (to a lesser extent). Meropenem and doripenem resulted in a distinct binding profile, exclusively inhibiting PBP3 and PBP5. Based on these results, chemical probes were designed and synthesized using the meropenem core to target PBP3. These probes enabled examination of PBP3 activity in live $B$. subtilis cells, which mainly localized as a ring during early divisional stages and moved to the central septal region and the division site during later stages. This finding is unprecedented and suggests a potential role for PBP3 during the division of $B$. subtilis cells. Overall, this work highlights the significance of PBP-selective chemical tools to complement the existing molecular and cell biology tools to augment our understanding of bacterial growth and division processes.

\section{MATERIALS AND METHODS}

$\beta$-Lactam titration and detection of PBPs, synthesis and characterization of probes, microscopy, and additional experimental protocols are discussed in detail in the Supporting Information.

\section{Supplementary Material}

Refer to Web version on PubMed Central for supplementary material.

\section{ACKNOWLEDGMENTS}

We thank O. Kocaoglu for performing initial titration studies. This work was supported by the National Institutes of Health (R01 GM128439-01A1 to E.E.C. and R35 GM131783 to D.B.K.), a Sloan Research Fellow Award (E.E.C.), 
a University of Minnesota Interdisciplinary Doctoral Fellowship (S.S.), and the University of Minnesota Department of Chemistry. The authors thank Y. Zhao and P. Villalta for assistance with the operation mass spectrometers. Mass spectrometry was carried out in the Analytical Biochemistry Shared Resource of the Masonic Cancer Center, University of Minnesota, supported in part by the Cancer Center Support Grant NIH CA077598.

\section{REFERENCES}

(1). Vollmer W, Blanot D, and de Pedro MA (2008) Peptidoglycan structure and architecture. FEMS Microbiol Rev. 32, 149-167. [PubMed: 18194336]

(2). Loskill P, Pereira PM, Jung P, Bischoff M, Herrmann M, Pinho MG, and Jacobs K (2014) Reduction of the peptidoglycan crosslinking causes a decrease in stiffness of the Staphylococcus aureus cell envelope. Biophys. J 107, 1082-1089. [PubMed: 25185544]

(3). Macheboeuf P, Contreras-Martel C, Job V, Dideberg O, and Dessen A (2006) Penicillin binding proteins: key players in bacterial cell cycle and drug resistance processes. FEMS Microbiol Rev. 30, 673-691. [PubMed: 16911039]

(4). Sauvage E, Kerff F, Terrak M, Ayala JA, and Charlier P (2008) The penicillin-binding proteins: structure and role in peptidoglycan biosynthesis. FEMS Microbiol Rev. 32, 234-258. [PubMed: 18266856]

(5). Bush K, and Bradford PA (2016) beta-Lactams and beta-Lactamase Inhibitors: An Overview. Cold Spring Harbor Perspect. Med 6, a025247.

(6). Papp-Wallace KM, Endimiani A, Taracila MA, and Bonomo RA (2011) Carbapenems: past, present, and future. Antimicrob. Agents Chemother 55, 4943-4960. [PubMed: 21859938]

(7). Zapun A, Contreras-Martel C, and Vernet T (2008) Penicillin-binding proteins and beta-lactam resistance. FEMS Microbiol Rev. 32, 361-385. [PubMed: 18248419]

(8). Waxman DJ, and Strominger JL (1983) Penicillin-binding proteins and the mechanism of action of beta-lactam antibiotics. Annu. Rev. Biochem 52, 825-869. [PubMed: 6351730]

(9). Kocaoglu O, Calvo RA, Sham LT, Cozy LM, Lanning BR, Francis S, Winkler ME, Kearns DB, and Carlson EE (2012) Selective penicillin-binding protein imaging probes reveal substructure in bacterial cell division. ACS Chem. Biol 7, 1746-1753. [PubMed: 22909777]

(10). Sharifzadeh S, Boersma MJ, Kocaoglu O, Shokri A, Brown CL, Shirley JD, Winkler ME, and Carlson EE (2017) Novel Electrophilic Scaffold for Imaging of Essential Penicillin-Binding Proteins in Streptococcus pneumoniae. ACS Chem. Biol 12, 2849-2857. [PubMed: 28990753]

(11). Wei Y, Havasy T, McPherson DC, and Popham DL (2003) Rod shape determination by the Bacillus subtilis class B penicillin-binding proteins encoded by $p b p A$ and $p b p H$. J. Bacteriol 185 , 4717-4726. [PubMed: 12896990]

(12). Sassine J, Xu M, Sidiq KR, Emmins R, Errington J, and Daniel RA (2017) Functional redundancy of division specific penicillin-binding proteins in Bacillus subtilis. Mol. Microbiol 106, 304-318. [PubMed: 28792086]

(13). Morales Angeles D, Liu Y, Hartman AM, Borisova M, de Sousa Borges A, de Kok N, Beilharz K, Veening JW, Mayer C, Hirsch AK, and Scheffers DJ (2017) Pentapeptide-rich peptidoglycan at the Bacillus subtilis cell-division site. Mol. Microbiol 104, 319-333. [PubMed: 28118510]

(14). Scheffers DJ, Jones LJ, and Errington J (2004) Several distinct localization patterns for penicillin-binding proteins in Bacillus subtilis. Mol. Microbiol 51, 749-764. [PubMed: 14731276]

(15). Margolin W (2012) The price of tags in protein localization studies. J. Bacteriol 194, 6369-6371. [PubMed: 22961859]

(16). Fura JM, Kearns D, and Pires MM (2015) D-Amino Acid Probes for Penicillin Binding Proteinbased Bacterial Surface Labeling. J. Biol. Chem 290, 30540-30550. [PubMed: 26499795]

(17). Hsu YP, Rittichier J, Kuru E, Yablonowski J, Pasciak E, Tekkam S, Hall E, Murphy B, Lee TK, Garner EC, Huang KC, Brun YV, and VanNieuwenhze MS (2017) Full color palette of fluorescent D-amino acids for in situ labeling of bacterial cell walls. Chem. Sci 8, 6313-6321. [PubMed: 28989665] 
(18). Kuru E, Hughes HV, Brown PJ, Hall E, Tekkam S, Cava F, de Pedro MA, Brun YV, and VanNieuwenhze MS (2012) In Situ probing of newly synthesized peptidoglycan in live bacteria with fluorescent D-amino acids. Angew. Chem., Int. Ed 51, 12519-12523.

(19). Radkov AD, Hsu YP, Booher G, and VanNieuwenhze MS (2018) Imaging Bacterial Cell Wall Biosynthesis. Annu. Rev. Biochem 87, 991-1014. [PubMed: 29596002]

(20). Chambers HF, Sachdeva MJ, and Hackbarth CJ (1994) Kinetics of penicillin binding to penicillin-binding proteins of Staphylococcus aureus. Biochem. J 301 (Pt 1), 139-144. [PubMed: 8037661]

(21). Williamson R, Hakenbeck R, and Tomasz A (1980) In vivo interaction of beta-lactam antibiotics with the penicillin-binding proteins of Streptococcus pneumoniae. Antimicrob. Agents Chemother 18, 629-637. [PubMed: 7447421]

(22). Curtis NA, Orr D, Ross GW, and Boulton MG (1979) Competition of beta-lactam antibiotics for the penicillin-binding proteins of Pseudomonas aeruginosa, Enterobacter cloacae, Klebsiella aerogenes, Proteus rettgeri, and Escherichia coli: comparison with antibacterial activity and effects upon bacterial morphology. Antimicrob. Agents Chemother 16, 325-328. [PubMed: 116592]

(23). Zhao G, Meier TI, Kahl SD, Gee KR, and Blaszczak LC (1999) BOCILLIN FL, a sensitive and commercially available reagent for detection of penicillin-binding proteins. Antimicrob. Agents Chemother 43, 1124-1128. [PubMed: 10223924]

(24). Kocaoglu O, and Carlson EE (2015) Profiling of beta-lactam selectivity for penicillin-binding proteins in Escherichia coli strain DC2. Antimicrob. Agents Chemother 59, 2785-2790. [PubMed: 25733506]

(25). Kocaoglu O, Tsui HC, Winkler ME, and Carlson EE (2015) Profiling of beta-lactam selectivity for penicillin-binding proteins in Streptococcus pneumoniae D39. Antimicrob. Agents Chemother 59, 3548-3555. [PubMed: 25845878]

(26). Kocaoglu O, and Carlson EE (2013) Penicillin-binding protein imaging probes. Curr. Protoc Chem. Biol 5, 239-250. [PubMed: 24391095]

(27). Sharifzadeh S, Shirley JD, and Carlson EE (2018) Activity-Based Protein Profiling Methods to Study Bacteria: The Power of Small-Molecule Electrophiles. Curr. Top. Microbiol. Immunol 420, $23-48$.

(28). Blumberg PM, and Strominger JL (1972) Isolation by covalent affinity chromatography of the penicillin-binding components from membranes of Bacillus subtilis. Proc. Natl. Acad. Sci. U. S. A 69, 3751-3755. [PubMed: 4630162]

(29). Foster SJ, and Popham DL (2002) Structure and synthesis of cell wall, spore cortex, teichoic acids, S-layers, and capsules In Bacillus subtilis and its close relatives: from genes to cells, Sonenshein L, Losick R, and Hoch JA, (Eds.), American Society for Microbiology, Washington, D.C.

(30). Atrih A, Bacher G, Allmaier G, Williamson MP, and Foster SJ (1999) Analysis of peptidoglycan structure from vegetative cells of Bacillus subtilis 168 and role of PBP 5 in peptidoglycan maturation. J. Bacteriol 181, 3956-3966. [PubMed: 10383963]

(31). Meador-Parton J, and Popham DL (2000) Structural analysis of Bacillus subtilis spore peptidoglycan during sporulation. J. Bacteriol 182, 4491-4499. [PubMed: 10913082]

(32). Popham DL (2002) Specialized peptidoglycan of the bacterial endospore: the inner wall of the lockbox. Cell. Mol. Life Sci 59, 426-433. [PubMed: 11964121]

(33). Reusch VM Jr., Hale SG, and Hurly BJ (1982) Levels of cell wall enzymes in endospores and vegetative cells of Bacillus subtilis. J. Bacteriol 152, 1147-1153. [PubMed: 6815162]

(34). McPherson DC, Driks A, and Popham DL (2001) Two class A high-molecular-weight penicillinbinding proteins of Bacillus subtilis play redundant roles in sporulation. J. Bacteriol 183, 60466053. [PubMed: 11567005]

(35). Buchanan CE, and Strominger JL (1976) Altered penicillin-binding components in penicillinresistant mutants of Bacillus subtilis. Proc. Natl. Acad. Sci. U. S. A 73, 1816-1820. [PubMed: 819927]

(36). Kleppe G, and Strominger JL (1979) Studies of the high molecular weight penicillin-binding proteins of Bacillus subtilis. J. Biol. Chem 254, 4856-4862. [PubMed: 108285] 
(37). Horikawa S, and Ogawara H (1980) Penicillin-binding proteins in Bacillus subtilis. The effects on penicillin-binding proteins and the antibacterial activities of beta-lactams. J. Antibiot 33, 614619.

(38). Reynolds PE, Shepherd ST, and Chase HA (1978) Identification of the binding protein which may be the target of penicillin action in Bacillus megaterium. Nature 271, 568-570. [PubMed: 414142]

(39). Matsuhashi S, Kamiryo T, Blumberg PM, Linnett P, Willoughby E, and Strominger JL (1974) Mechanism of action and development of resistance to a new amidino penicillin. J. Bacteriol 117, 578-587. [PubMed: 4590478]

(40). Park JT, and Burman L(1973) FL-1060: a new penicillin with a unique mode of action. Biochem. Biophys. Res. Commun 51, 863-868. [PubMed: 4574155]

(41). James R, Haga JY, and Pardee AB (1975) Inhibition of an early event in the cell division cycle of Escherichia coli by FL1060, an amidinopenicillanic acid. J. Bacteriol 122, 1283-1292. [PubMed: 168179]

(42). Shohayeb M, and Chopra I (1987) Mutations affecting penicillin-binding proteins 2a, 2b and 3 in Bacillus subtilis alter cell shape and peptidoglycan metabolism. Microbiology 133, 1733-1742.

(43). Murray T, Popham DL, Pearson CB, Hand AR, and Setlow P (1998) Analysis of outgrowth of Bacillus subtilis spores lacking penicillin-binding protein 2a. J. Bacteriol 180, 6493-6502. [PubMed: 9851991]

(44). Yanouri A, Daniel RA, Errington J, and Buchanan CE (1993) Cloning and sequencing of the cell division gene $p b p B$, which encodes penicillin-binding protein $2 \mathrm{~B}$ in Bacillus subtilis. J. Bacteriol 175, 7604-7616. [PubMed: 8244929]

(45). Kocaoglu O, Tsui H-CT, Winkler ME, and Carlson EE (2015) Profiling of $\beta$-Lactam Selectivity for Penicillin-Binding Proteins in Streptococcus pneumoniae D39. Antimicrob. Agents Chemother 59, 3548-3555. [PubMed: 25845878]

(46). Blumberg PM, and Strominger JL (1972) Five penicillin-binding components occur in Bacillus subtilis membranes. J. Biol. Chem 247, 8107-8113. [PubMed: 4344991]

(47). Kleppe G, Yu W, and Strominger JL (1982) Penicillin-binding proteins in Bacillus subtilis mutants. Antimicrob. Agents Chemother 21, 979-983. [PubMed: 6810758]

(48). Neyman SL, and Buchanan CE (1985) Restoration of vegetative penicillin-binding proteins during germination and outgrowth of Bacillus subtilis spores: relationship of individual proteins to specific cell cycle events. J. Bacteriol 161, 164-168. [PubMed: 3917999]

(49). Spratt BG, and Pardee AB (1975) Penicillin-binding proteins and cell shape in E. coli. Nature 254, 516-517. [PubMed: 1091862]

(50). Dougherty TJ, Kennedy K, Kessler RE, and Pucci MJ (1996) Direct quantitation of the number of individual penicillin-binding proteins per cell in Escherichia coli. J. Bacteriol 178, 6110-6115. [PubMed: 8892807]

(51). McPherson DC, and Popham DL (2003) Peptidoglycan synthesis in the absence of class A penicillin-binding proteins in Bacillus subtilis. J. Bacteriol 185, 1423-1431. [PubMed: 12562814]

(52). Popham DL, and Setlow P (1995) Cloning, nucleotide sequence, and mutagenesis of the Bacillus subtilis ponA operon, which codes for penicillin-binding protein (PBP) 1 and a PBP-related factor. J. Bacteriol 177, 326-335. [PubMed: 7814321]

(53). Popham DL, and Setlow P (1994) Cloning, nucleotide sequence, mutagenesis, and mapping of the Bacillus subtilis pbpD gene, which codes for penicillin-binding protein 4. J. Bacteriol 176, 7197-7205. [PubMed: 7961491]

(54). Popham DL, and Setlow P (1996) Phenotypes of Bacillus subtilis mutants lacking multiple class A high-molecular-weight penicillin-binding proteins. J. Bacteriol 178, 2079-2085. [PubMed: 8606187]

(55). Pedersen LB, Angert ER, and Setlow P (1999) Septal localization of penicillin-binding protein 1 in Bacillus subtilis. J. Bacteriol 181, 3201-3211. [PubMed: 10322023]

(56). Queenan AM, Shang W, Flamm R, and Bush K (2010) Hydrolysis and inhibition profiles of betalactamases from molecular classes A to D with doripenem, imipenem, and meropenem. Antimicrob. Agents Chemother 54, 565-569. [PubMed: 19884379] 
(57). Jackson JJ, and Kropp H (1992) beta-Lactam antibiotic-induced release of free endotoxin: in vitro comparison of penicillin-binding protein (PBP) 2-specific imipenem and PBP 3-specific ceftazidime. J. Infect. Dis 165, 1033-1041. [PubMed: 1583320]

(58). Horii T, Ichiyama S, Ohta M, and Kobayashi M (1999) Relationship between morphological changes and endotoxin release induced by carbapenems in Pseudomonas aeruginosa. J. Med. Microbiol 48, 309-315. [PubMed: 10334599]

(59). Sumita Y, and Fakasawa M (1995) Potent activity of meropenem against Escherichia coli arising from its simultaneous binding to penicillin-binding proteins 2 and 3. J. Antimicrob. Chemother 36, 53-64. [PubMed: 8537284]

(60). Trautmann M, Heinemann M, Zick R, Moricke A, Seidelmann M, and Berger D (1998) Antibacterial activity of meropenem against Pseudomonas aeruginosa, including antibioticinduced morphological changes and endotoxin-liberating effects. Eur. J. Clin. Microbiol. Infect. Dis 17, 754-760. [PubMed: 9923514]

(61). Davies TA, Shang W, Bush K, and Flamm RK (2008) Affinity of doripenem and comparators to penicillin-binding proteins in Escherichia coli and Pseudomonas aeruginosa. Antimicrob. Agents Chemother 52, 1510-1512. [PubMed: 18250190]

(62). Murray T, Popham DL, and Setlow P (1996) Identification and characterization of $p b p C$, the gene encoding Bacillus subtilis penicillin-binding protein 3. J. Bacteriol 178, 6001-6005. [PubMed: 8830698] 


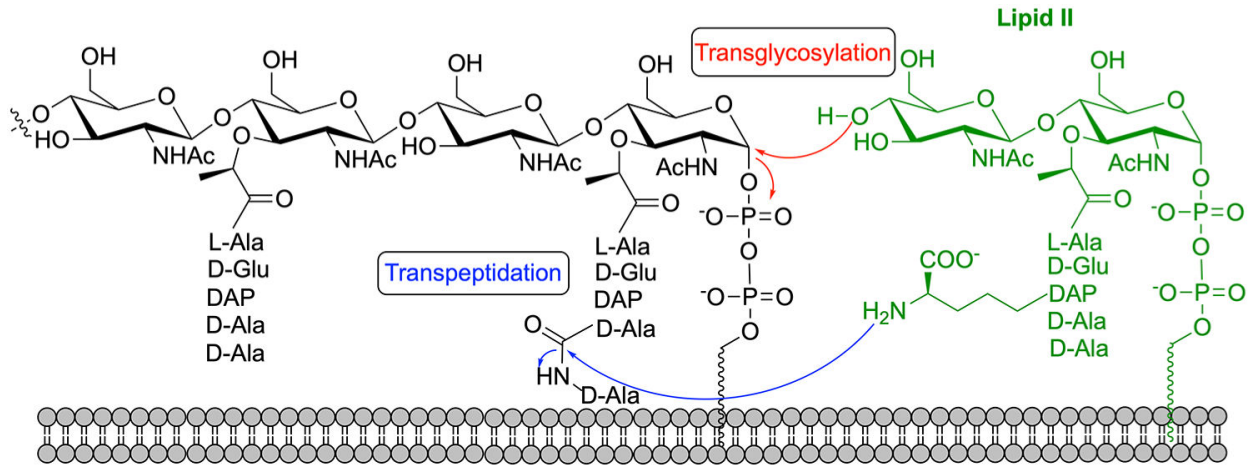

Figure 1.

Bacterial PG is a polymeric structure composed of repeating units of $\mathrm{N}$-acetylglucosamine and $N$-acetylmuramic acid carrying pentapeptide side chains (stem peptide). PBP enzymes catalyze the polymerization of PG subunits, also known as lipid II to form PG chains (transglycosylation). PBPs are also responsible for transpeptidation reaction, which crosslinks the stem peptides from different PG chains. Composition of B. subtilis $\mathrm{PG}$ is shown in this figure (DAP = 2,6-diaminopimelic acid). 
Aztreonam

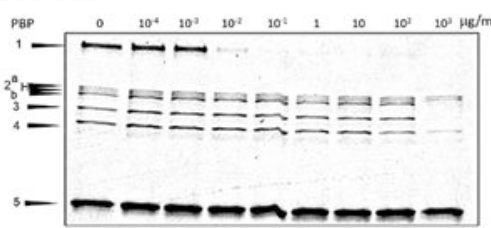

Cefuroxime

PQP $\quad \begin{array}{llllllllll}0 & 10^{4} & 10^{4} & 10^{2} & 10^{-4} & 1 & 10 & 10^{2} & 10^{4} & \mu \mathrm{gg} / \mathrm{ml}\end{array}$

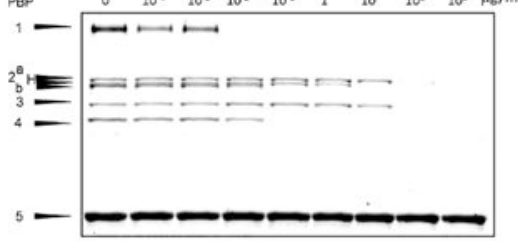

Cephalothin

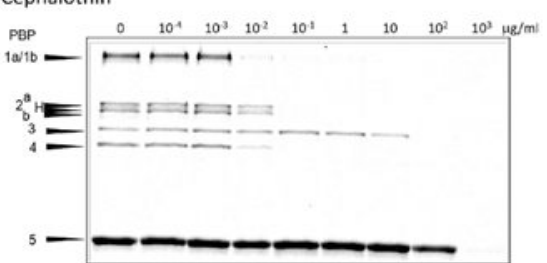

Faropenem

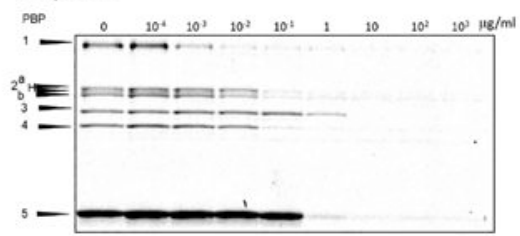

Cefotaxime
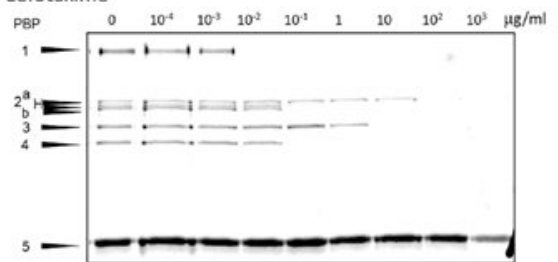

Cefsulodin

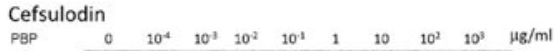

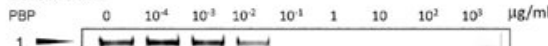

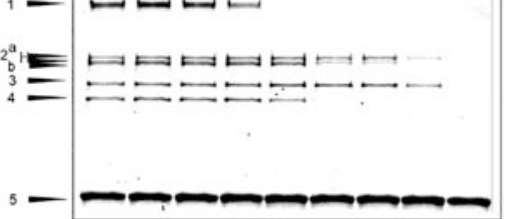

Piperacillin

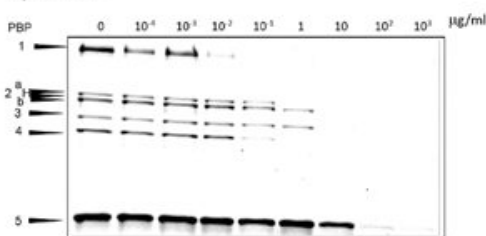

Ceftriaxone

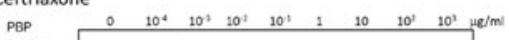

$10^{4} \quad 10^{\circ}$

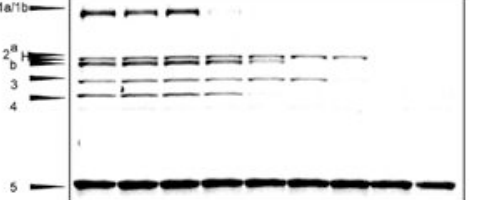

Cefoxitin

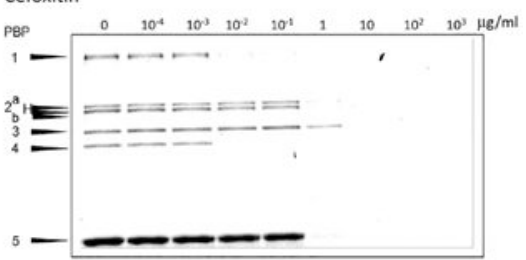

Figure 2.

Complete inhibition of PBP1 by aztreonam, faropenem, piperacillin, and cephalosporin compounds. Representative SDS-PAGE gel images for titration of $B$. subtilis PY79 cells by these antibiotics over a defined concentration range. Gel band quantitation for the presented gels with the standard deviations of the results from two independent experiments are plotted in Figure S2. 

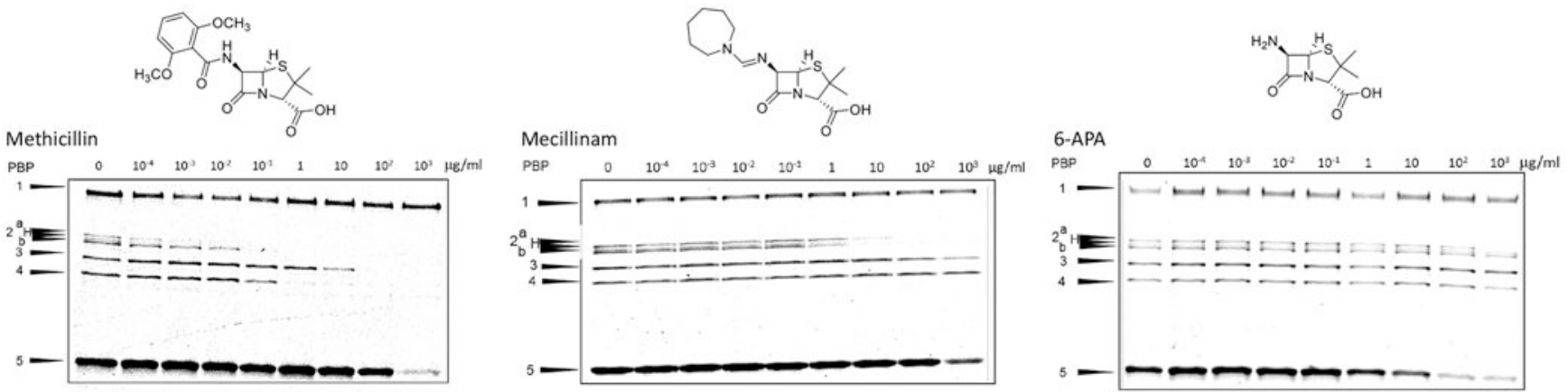

Figure 3.

Representative SDS-PAGE gel images for inhibition of the PBPs by methicillin (left), mecillinam (center), and (+)-6-aminopenicillanic acid (right) in B. subtilis over a range of antibiotic concentrations. Whole cells were treated with various concentrations of antibiotics and subsequently labeled with $5 \mu \mathrm{g} / \mathrm{mL}$ Boc-FL. Most penicillins were potent inhibitors of PBP2a and PBP2b, as exemplified by methicillin. Mecillinam exclusively inhibited these two PBPs over the tested concentration range. 6-APA is a weak inhibitor of PBP5 activity. 


\section{A Doripenem}

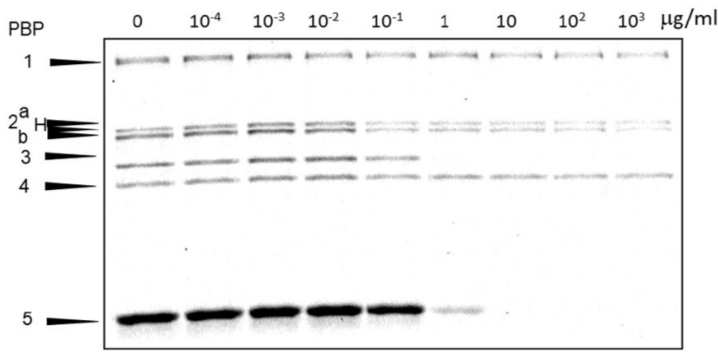

B

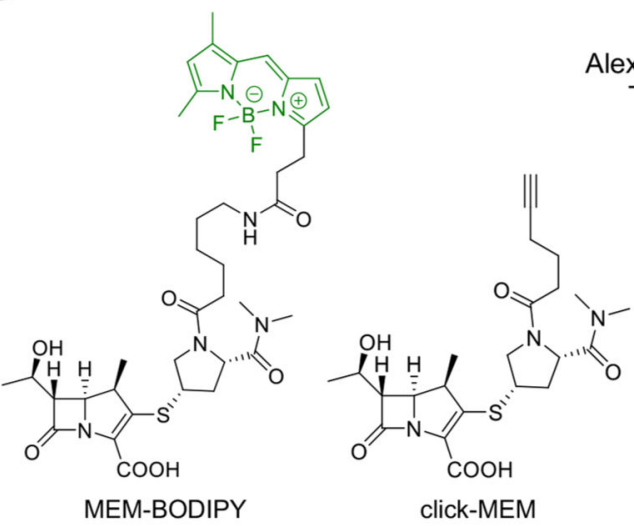

C
Meropenem

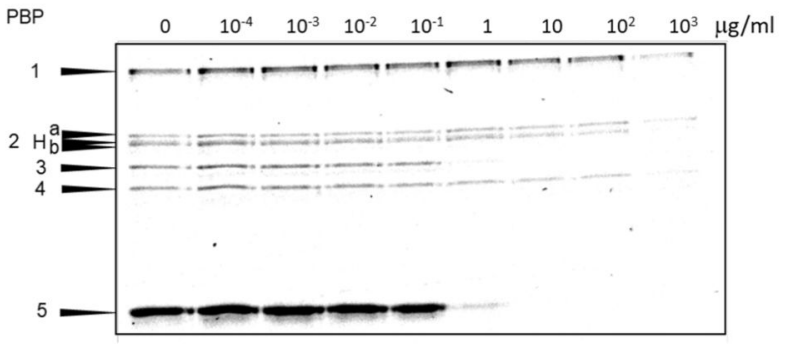

click-MEM AlexaFluor488-azide TCEP, TBTA, Cu

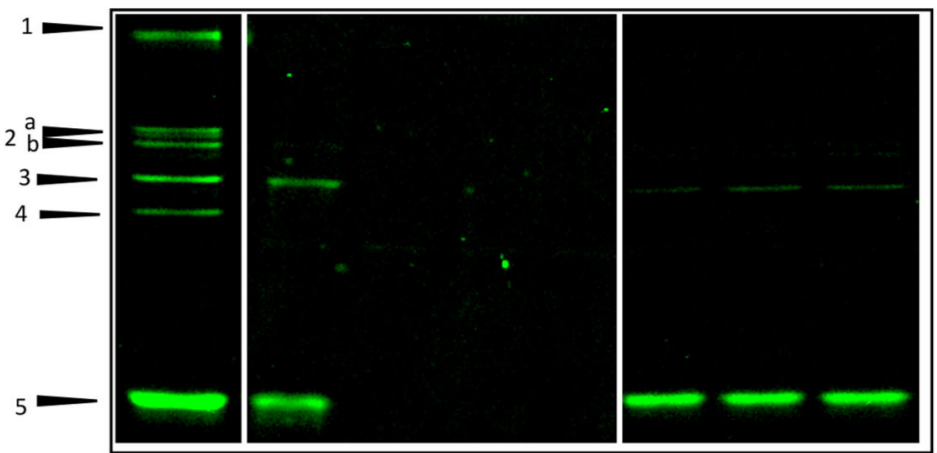

Figure 4.

Probes to target PBP3 and PBP5 in B. subtilis. (A) Doripenem and meropenem selectively target PBPs 3 and 5. Selective and complete inhibition of PBP3 and PBP5 is observed at $\sim 1$ $\mu \mathrm{g} / \mathrm{mL}$ of meropenem, corresponding to $2.6 \mu \mathrm{M}$. (B) Chemical structure of fluorescent (MEM-BODIPY) and clickable meropenem analogues (click-MEM). (C) PBP labeling profile of meropenem-based probes in B. subtilis cells assessed by SDS-PAGE. 1:10 $\mu \mathrm{M}$ Boc-FL (control), 2-5: treatment with $5 \mu \mathrm{M}$ click-MEM $(2,3)$ or no probe $(4,5)$ followed by reaction with different combinations of click reagents. Only lane 2 , where cells were treated with the probe and reacted with AlexaFluor488-azide in the presence of all click reagents, resulted in fluorescent labeling of PBPs. 6-8: treatment with $2 \mu \mathrm{M}$ MEM-BODIPY for $10 \mathrm{~min}$ (6), $20 \mathrm{~min}$ (7), or $30 \mathrm{~min}$ (8). Labeling intensity plateaus after $20 \mathrm{~min}$. 


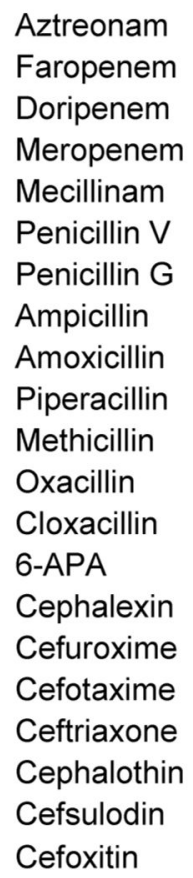

Aztreonam

Faropenem

Doripenem

Meropenem

Mecillinam

Penicillin G

Ampicillin

Amoxicillin

Piperacillin

Methicillin

Oxacillin

Cloxacillin

6-APA

Cephalexin

Cefuroxime

Ceftriaxone

Cephalothin

Cefoxitin

\begin{tabular}{|c|c|c|c|c|l|l}
\hline PBP1a/1b & PBP2a & PBPH/2b & PBP3 & PBP4 & PBP5 & MIC \\
\hline 4 & 84 & 82 & 100 & 52 & 100 & 16 \\
6 & 19 & 10 & 97 & 14 & 78 & 0.125 \\
\hline 59 & 40 & 36 & 63 & 69 & 78 & 0.0625 \\
\hline 100 & 86 & 75 & 84 & 79 & 86 & 0.0625 \\
\hline 68 & 28 & 12 & 83 & 92 & 91 & 16 \\
\hline 38 & 0 & 1 & 2 & 19 & 7 & 32 \\
\hline 52 & 0 & 0 & 3 & 14 & 5 & 16 \\
\hline 19 & 1 & 2 & 6 & 5 & 36 & 8 \\
\hline 25 & 3 & 3 & 0 & 8 & 56 & 4 \\
\hline 3 & 1 & 0 & 0 & 0 & 6 & 64 \\
\hline 74 & 4 & 10 & 100 & 54 & 100 & 0.25 \\
70 & 50 & 54 & 91 & 13 & 99 & 0.25 \\
67 & 47 & 63 & 100 & 10 & 78 & 0.125 \\
\hline 100 & 53 & 77 & 84 & 71 & 16 & 128 \\
\hline 39 & 1 & 15 & 98 & 52 & 100 & 0.5 \\
\hline 1 & 94 & 43 & 100 & 3 & 97 & 0.125 \\
\hline 1 & 100 & 16 & 100 & 10 & 100 & 0.0625 \\
\hline 1 & 90 & 45 & 92 & 13 & 92 & 0.25 \\
7 & 28 & 25 & 100 & 13 & 100 & 0.0312 \\
\hline 1 & 89 & 27 & 99 & 3 & 99 & 8 \\
2 & 28 & 9 & 54 & 3 & 5 & 1 \\
\hline
\end{tabular}

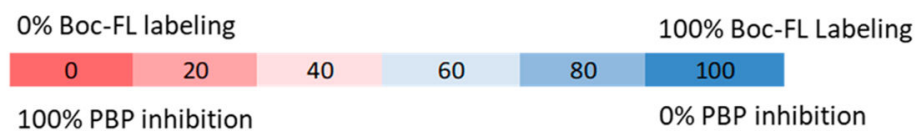

Figure 5.

PBP inhibition at MIC illustrated as a heat map to summarize the level of PBP inhibition at growth inhibitory concentrations. The number in each cell is the average percent Boc-FL labeling of each PBP at the MIC from two separate experiments (i.e., low numbers equate to more protein inhibition). Because titrations were done in 10-fold intervals, the Boc-FL labeling at the concentration closest to the MIC was used. Low Boc-FL labeling (red) demonstrates high inhibition of that PBP at that concentration, whereas blue indicates high levels of Boc-FL labeling/low PBP inhibition. 


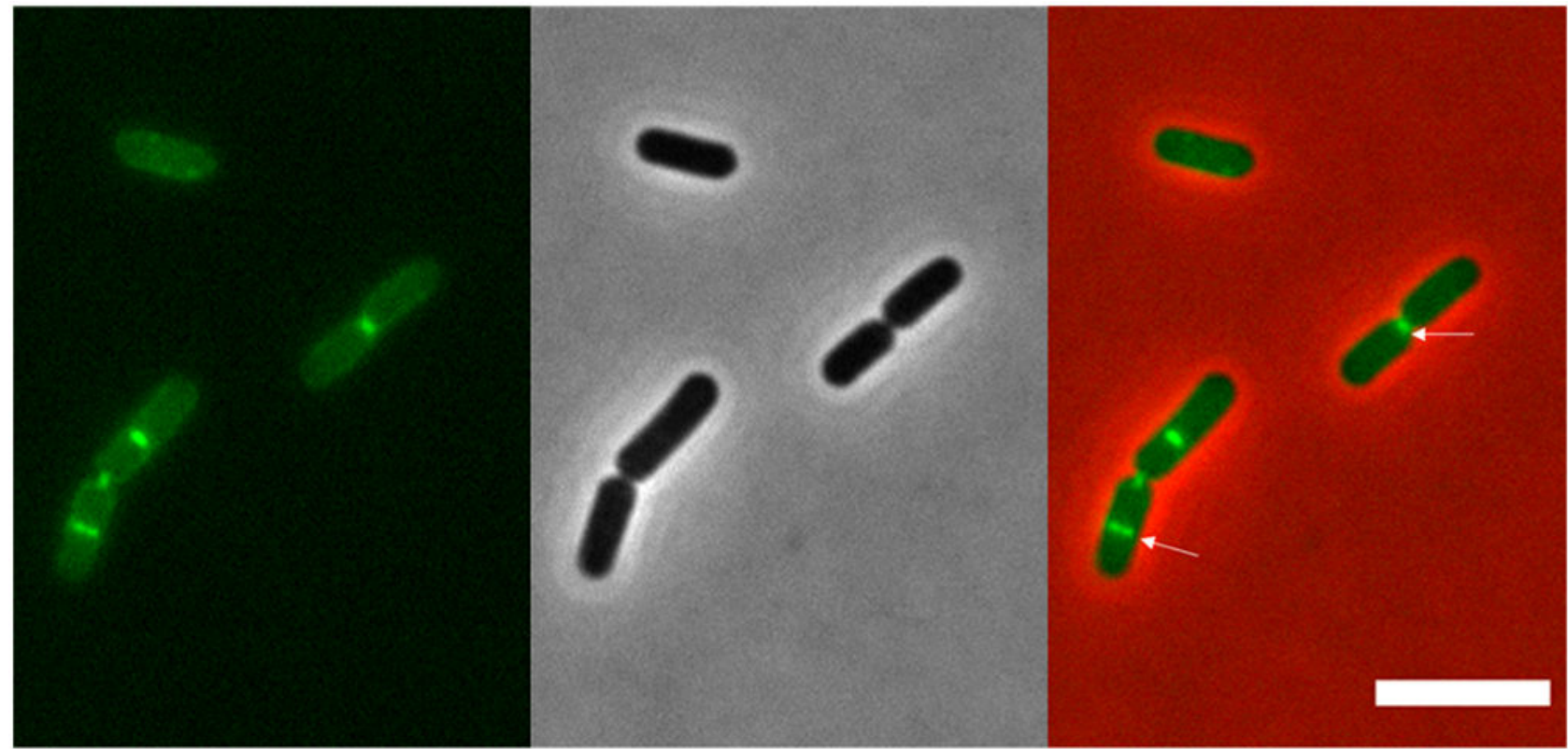

Figure 6.

Visualization of PBP3 activity in live $B$. subtilis DK654 cells ( $\triangle$ dac $A)$. Exponentially growing $B$. subtilis DK654 cells were labeled with $2 \mu \mathrm{M}$ MEM-BODIPY FL and imaged at $100 \times$ magnification. Fluorescent image is shown on the left, phase contrast in the middle, and both overlaid on the right. PBP3 activity localizes to septal region in early- to middivisional stages and later, concentrates at the division site (indicated by the white arrows). Scale bar $=5 \mu \mathrm{m}$. 


\section{\.}

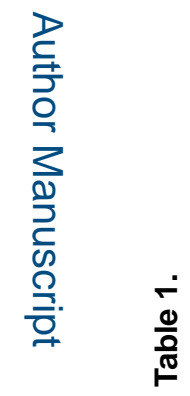

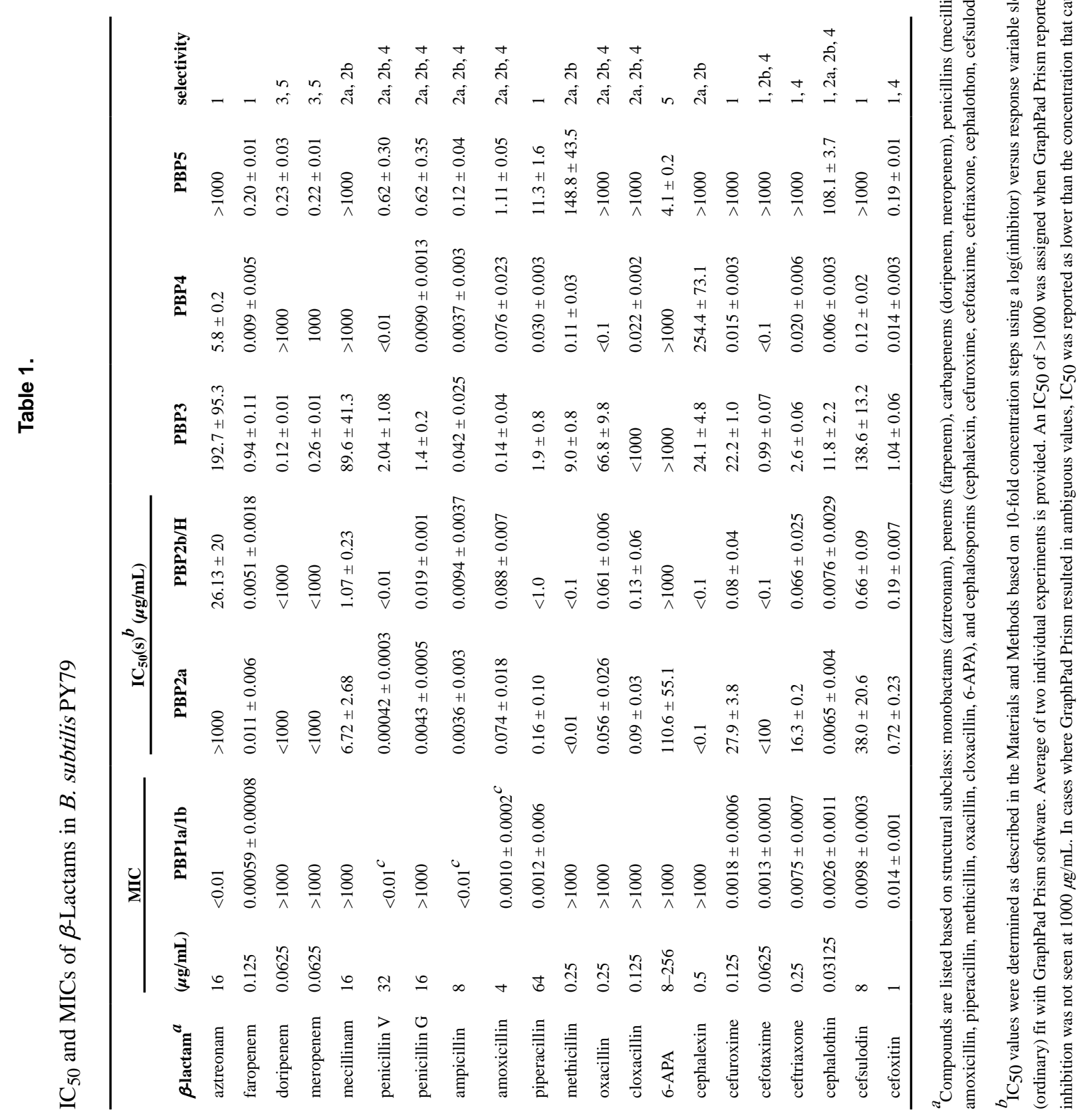

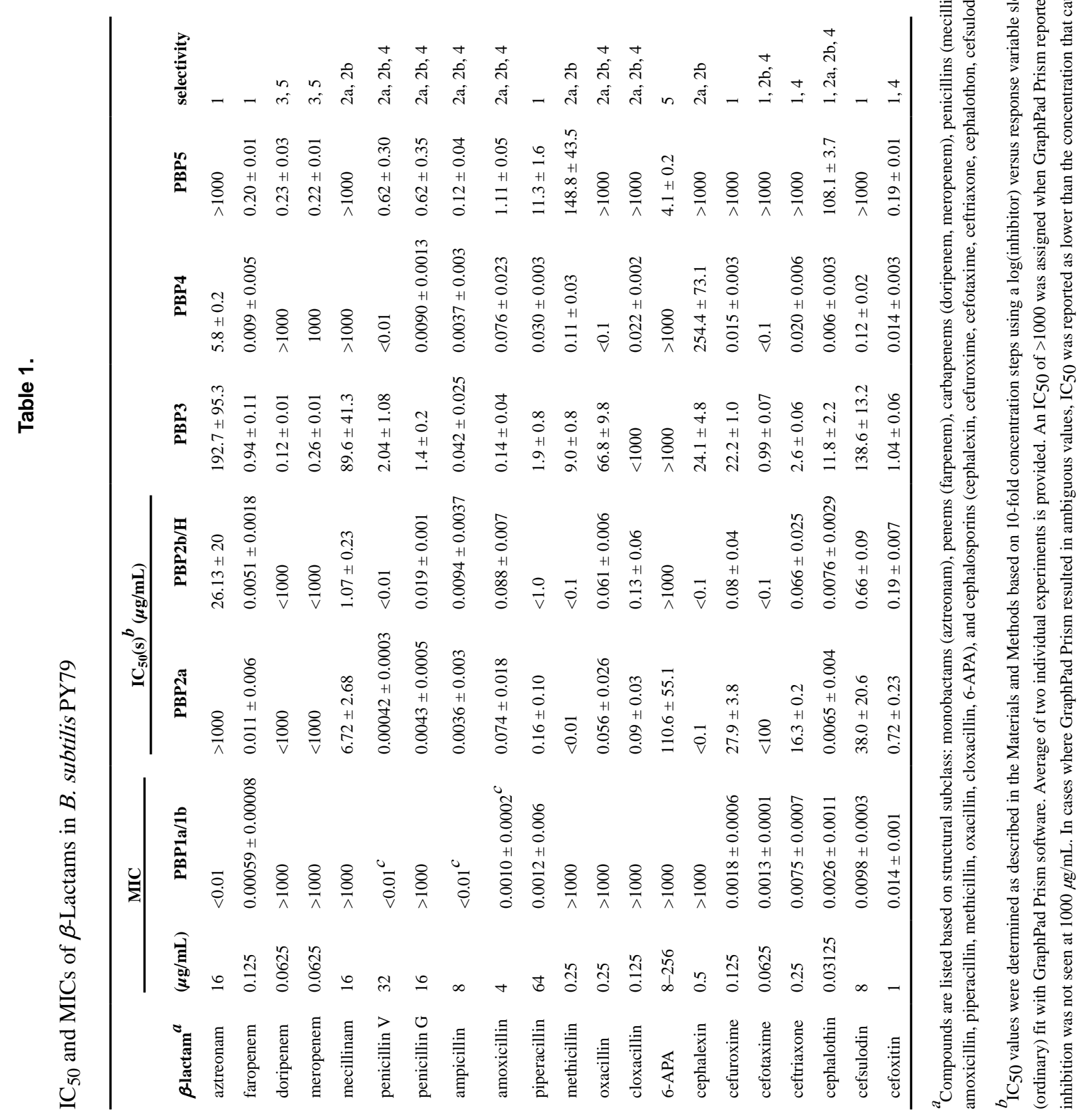

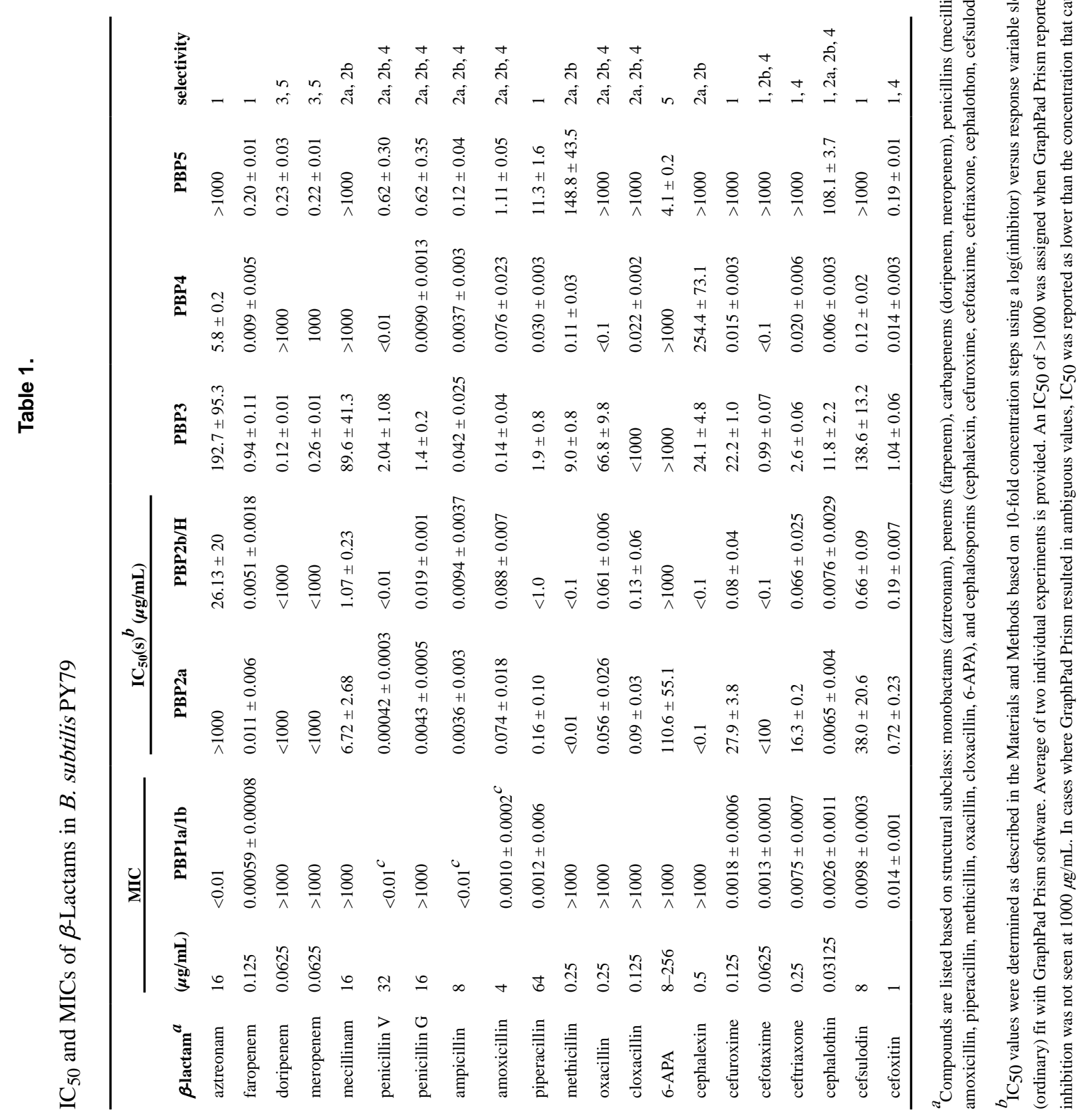

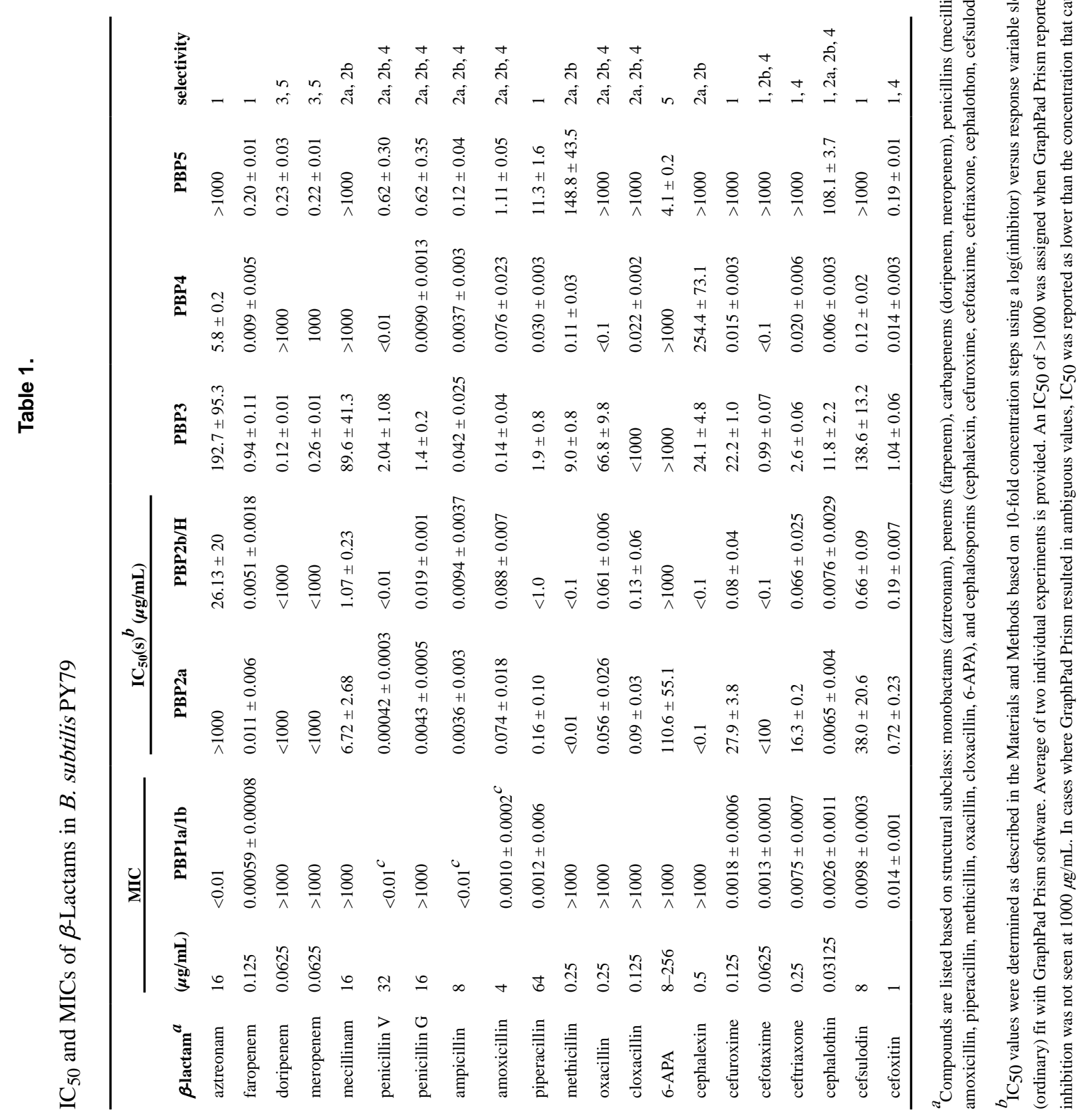

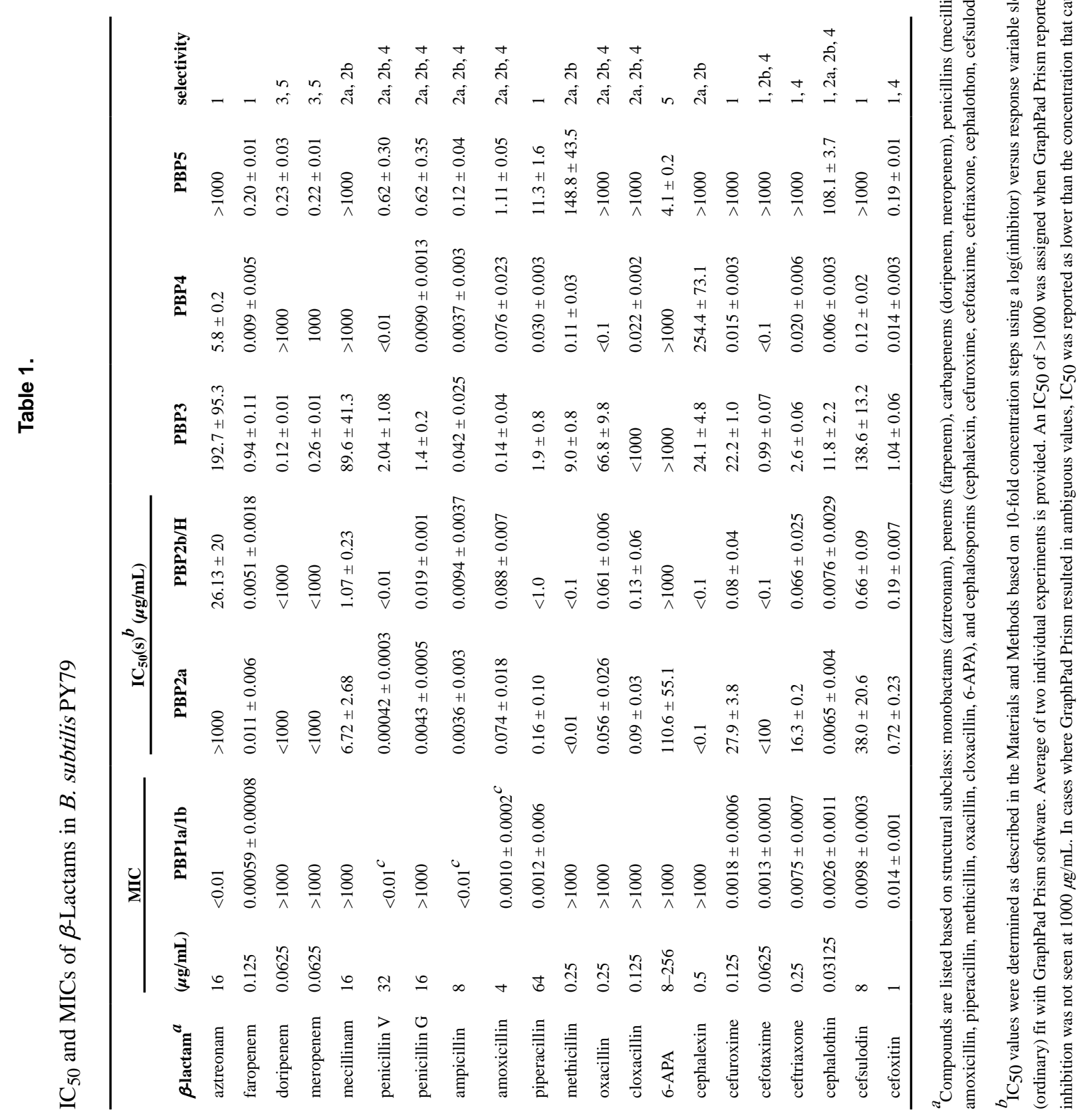

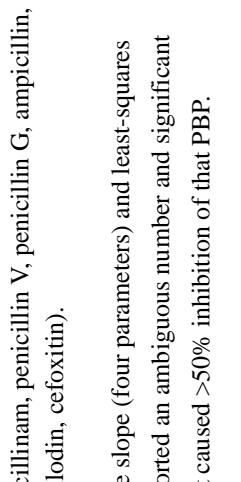
ACS Chem Biol. Author manuscript; available in PMC 2021 January 05. 


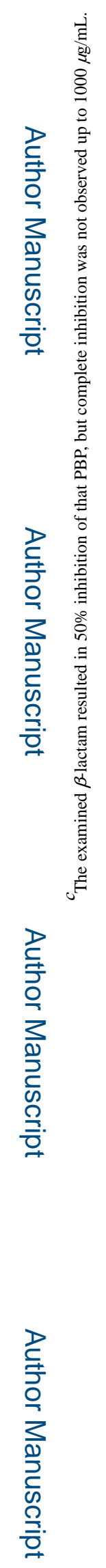

